\title{
PROGRAMA BASTA: RELATOS E REFLEXÕES SOBRE A VIOLÊNCIA CONTRA A MULHER
}

\author{
PROGRAM BASTA: A REPORT \\ AND SOME REFLETIONS ON \\ VIOLENCE AGAINST WOMEN
}

\author{
SOUZA, José Ricardo' \\ ALMEIDA, Ana Beatriz Baggio ${ }^{2}$ \\ ALVES, Silvia Okabe ${ }^{3}$ \\ EKUNI, Roberta ${ }^{4}$ \\ GARCIA, Lucyellen Roberta Dias ${ }^{5}$ \\ LOPES, Soraya Saad ${ }^{6}$ \\ TAKAHARA, Erica Akemi ${ }^{7}$
}

\section{RESUMO}

O presente artigo tem como objetivo apresentar um relato de experiência das ações desenvolvidas pelo Programa Basta, o qual é supervisionado e executado pelo Projeto de Extensão Universitária - Patronato Municipal de Jacarezinho, da Universidade Estadual do Norte do Paraná - UENP. O presente relato engloba o período de agosto à dezembro de 2014. Os participantes autores de violência doméstica, encaminhados ao Patronato Municipal, mediante determinação judicial advinda da vara criminal da comarca de Jacarezinho-PR. Durante esse período, houve formação de 4 grupos, com um total de treze participantes. As reuniões aconteceram semanalmente, durante oito semanas, com duração de aproximadamente uma hora. Como resultado, foi possível perceber avanços no que tange a fiscalização das alternativas penais no

\footnotetext{
1 Assistente Social graduado pela Universidade Estadual de Londrina (UEL), Brasil. Especialização em Gestão Pública pela Universidade Estadual de Ponta Grossa (UEPG). Brasil. E-mail: souza192009@hotmail.com

2 Assistente Social graduada pela Universidade Estadual de Ponta Grossa (UEPG). Especialização em Gestão na Área Social pela Faculdade da Lapa (FAEL). E-mail: anabeatrizbaggio91@gmail.com

3 Psicóloga graduada pela Universidade Paulista (UNIP), Brasil. Especialização em Psicopedagogia pela Faculdade de Ciências de Wenceslau Braz (FACIBRA), Brasil. E-mail: silviaokabe@hotmail.com.

4 Professora da Universidade Estadual do Norte do Paraná (UENP). Aluna do curso de Doutorado em Psicobiologia da Universidade Federal de São Paulo (UNIFESP), Brasil. E-mail: robertaekuni@uenp.edu.br

5 Professora da Universidade Estadual do Norte do Paraná (UENP). Aluna do curso de Doutorado em Direito Econômico da Universidade de São Paulo (USP), Brasil. E-mail: ludiasgarcia@uenp.edu.br

6 Professora da Universidade Estadual do Norte do Paraná (UENP), Brasil. Mestrado em Ciência Jurídica pela Universidade Estadual do Norte do Paraná (UENP), Brasil. E-mail: soraya-saad@hotmail.com

7 Assistente Social graduada pela Universidade Estadual de Londrina (UEL), Brasil. Aluna do curso de Especialização em Gestão em Saúde da Universidade Estadual de Ponta Grossa (UEPG), Brasil. E-mail: ericatakahara@hotmail.com
} 
município, como também um melhor entendimento sobre a violência contra a mulher e a internalização de uma nova conduta por parte dos integrantes dos grupos.

Palavras Chaves: Violência. Reflexão. Gênero. Mulher.

\begin{abstract}
This study aims to report the activities conducted by the Program Basta from August to December of 2014. It is supervised and developed by North of Paraná State University (UENP) through the outreach project Patronato Municipal of Jacarezinho/PR. The participants were offenders sent to Patronato Municipal by court order from criminal court of Jacarezinho/PR. There were thirteen participants who were divided into four groups. The groups had week meetings during eight weeks. Each meeting lasted approximately one hour. The study reveals advances in the law enforcement of Jacarezinho as well as a better understanding about violence against women and the internalization of rules of conduct by the group members.
\end{abstract}

Keywords: Violence. Reflections. Gender. Women.

\title{
Introdução
}

O Patronato Municipal de Jacarezinho foi criado a partir do Projeto de Lei Municipal n. 111/2013, sendo resultado de uma parceria firmada entre a Secretaria de Justiça - SEJU, a Secretaria da Ciência, Tecnologia e Ensino Superior - SETI, Universidade Estadual do Norte do Paraná - UENP e a Prefeitura Municipal de Jacarezinho. O mesmo encontra-se em funcionamento desde setembro de 2013, e, atualmente, conta com sede no fórum da Comarca de Jacarezinho.

De acordo com a lei federal, o Patronato constitui-se em um órgão de execução penal, com previsão legal no artigo 61, inciso VI, da Lei de Execução Penal. O objetivo deste órgáo é fiscalizar o cumprimento, pelo assistido, ou seja, aquele que cometeu determinado ato infracional, das medidas despenalizadoras (aquelas que afastam a punibilidade do acusado), fixadas em sede de suspensão condicional do processo, transaçáo penal e das penas restritivas de direitos, impostas em sentença criminal. Esse cumprimento ocorre junto às instituiçóes cadastradas ao Poder Judiciário que possuem interesse no recebimento de prestaçóes pecuniárias e prestaçóes de serviço.

De acordo com a Lei n. 9714198, artigo 45, inciso I, a prestação pecuniária consiste no pagamento de 1 (um) a 360 (trezentos e sessenta) salários mínimos, sendo este fixado em juízo, em favor das vítimas, seus dependentes, ou a entidades públicas e privadas com finalidades sociais. Em relação à medida de prestação de serviços à comunidade, de acordo com a referida lei, consiste na execução, por parte do condenado, de atividades gratuitas junto à comunidade ou entidades públicas: escolas, hospitais, entidades assistenciais, programas comunitários, dentre outros.

O Patronato conta com uma equipe multidisciplinar técnica composta por profissionais da área de direito, serviço social, psicologia, pedagogia e administração, além de estagiários e orientadores das respectivas áreas.

Segundo o teor da Lei n. 2895/2013, além da competência relacionada à fiscalizaçáo das alternativas penais em meio aberto, compete ao Patronato Municipal a realização de açóes que visem à reflexão acerca do delito cometido pelos assistidos, o que tem a intenção de levá-los a internalizar uma nova conduta, evitando, assim, a reincidência criminal.

De acordo com os ensinamentos de Oliveira (2011), as penas alternativas possuem, além do caráter punitivo, a dimensão social, a qual possibilita ao autor do delito a sua inserção e permanência no contexto em que vive, evitando que ele fique privado de liberdade e seja estigmatizado pela sociedade. 
Nessa perspectiva, uma das alternativas penais que o Patronato Municipal desenvolve são os programas de acompanhamento específicos. Tais programas são ferramentas desenvolvidas pelo Patronato Central que têm por intuito a reinserção social dos que sáo acompanhados pelo serviço e a reduçáo da reincidência criminal. Os assistidos são incluídos nos programas de acordo com o delito que cometeram, mediante a realizaçáo de audiência e atendimento pela equipe técnica do Patronato. Fazem parte do rol de programas desenvolvidos o Programa Saiba, O Programa Basta, O Programa E-lerPró Labor e o Programa Blitz.

O Programa Saiba é pautado na perspectiva de redução de danos e busca acolher, discutir e refletir assuntos acerca do uso de drogas. Já o programa E-ler-Pró Labor busca conscientizar os assistidos sobre a importância da leitura e da educaçáo formal na sociedade atual, com vistas à reinserção no mercado de trabalho e profissionalização. Quanto ao programa Blitz, se destina aos infratores das leis de trânsito brasileiras, e busca, com suas açôes, conscientizar, elaborar senso crítico e levá-los a repensar os fatores acidentogênicos.

Outro programa desenvolvido pelo Patronato Municipal de Jacarezinho e eleito como enfoque da pesquisa científica é destinado a homens autores de violência doméstica. Trata-se do Programa Basta, que visa, por meio de açóes da equipe técnica, proporcionar um espaço de diálogo, reflexão e informação, a fim de levar os assistidos a repensar suas açôes, evitando, dessa forma, a reiteraçáo da conduta criminosa.

\section{Programa Basta: em busca de uma reflexáo em torno dos delitos envolvendo violência doméstica}

O Programa Basta veio para atender as demandas advindas da Lei ${ }^{\circ} 11.340 / 06^{\circ}$ Maria da Penha. Tal aparato legal foi resultado do trabalho e da mobilização do movimento feminista e de diversos setores da sociedade, que reivindicaram e pressionaram o governo para a criação de uma legislaçáo que garantisse a proteção integral às mulheres vítimas de violência.

A violência entre os gêneros, conforme entendimento de Meneghel et al. (2013), é um fenômeno histórico e advém quando existem relaçóes de poder assimétricas, estabelecendo hierarquias, podendo ser visíveis ou não. Ainda segundo a mesma autora, antes da Lei Maria da Penha, as ocorrências de casos de violência contra a mulher eram julgadas segundo a Lei n. 9.099/95, e a maioria dos casos eram considerados como crime de menor potencial ofensivo, com penas mais brandas, como, por exemplo, o pagamento de cestas básicas ou trabalho comunitário. Em situaçóes mais graves, a pena não excedia a dois anos de reclusão, o que aumentava ainda mais a sensação de impunidade.

A Lei Maria da Penha, além de criar mecanismos de proteção à mulher vítima de violência, instituiu também mecanismos para coibir e prevenir situaçóes de violência doméstica e familiar, trazendo, em seu bojo (art. 5), a definiçấo de violência como "qualquer ação ou omissão baseada no gênero que lhe cause morte, lesão, sofrimento físico, sexual ou psicológico e dano moral ou patrimonial” (BRASIL, 2006).

Ainda no tocante à estrutura da Lei Maria da Penha, esta tratou, em seu artigo $7^{\circ}$, acerca dos tipos de violência a que os sujeitos passivos do tipo penal estáo sujeitos e que são abrangidos pelo âmbito de proteção legal: a violência física; a violência psicológica; a violência sexual; a violência patrimonial e a violência moral. 
A fim de coibir todo o tipo de violência contra mulher, os artigos 34 e 35 da Lei Maria da Penha apontam a necessidade da promoção de serviços e programas de responsabilizaçáo e educaçáo aos autores de violências. É o que reza o art. 45, parágrafo único, ao afirmar que "nos casos de violência doméstica contra a mulher, o juiz poderá determinar o acompanhamento obrigatório do agressor em programas de recuperação e reeducação" (BRASIL, 2006).

Desta forma, o Patronato Municipal de Jacarezinho executa o Programa Basta, no qual os assistidos têm como uma das penas alternativas participarem dos oito encontros que o compóem. O Programa Basta é executado pela equipe técnica do Patronato Municipal e tem como objetivo oportunizar aos autores de violência doméstica um espaço de reflexão acerca de sua conduta delituosa. Buscou, com suas açóes, responsabilizá-los pelo ato violento cometido, além de ser um espaço de reflexão, interação e informaçáo, que objetiva a internalizaçáo de nova conduta por parte do agressor.

\section{Método desenvolvido na aplicaçáo do Programa Basta}

As açóes do Programa Basta foram desenvolvidas de acordo com as diretrizes do Patronato Central, o qual determina que os grupos devem ser formados por homens autores de violência doméstica, sendo estes beneficiados com as medidas de transação e suspensáo condicional do processo.

Com relação à duração e às temáticas abordadas, cada grupo participou de oito reuniốes semanais, com duraçáo média de uma hora cada. As temáticas compreenderam a legislação pertinente aos direitos da mulher, família, sociedade, violência de gênero, dentre outros temas. As reuniôes foram coordenadas e desenvolvidas pelos técnicos de serviço social e psicologia, que realizaram planejamento prévio, considerando as particularidades de cada grupo.

Com relaçáo aos grupos, foram formadas pelo Patronato Municipal de Jacarezinho quatro turmas, com dois, quatro, cinco e dois participantes, respectivamente. A faixa etária dos agressores atendidos variou de 21 e 62 anos de idade. As reunióes aconteceram nas salas de aula da Universidade Estadual do Norte do Paraná, no Centro de Ciências Sociais Aplicadas, onde a equipe técnica utilizou de recursos audiovisuais para condução das atividades.

Para que o agressor chegasse ao Programa Basta, foi necessário que, após realização de audiência, fosse atendido pela equipe multidisciplinar do Patronato Municipal, sendo, pois, de início, prestada assistência jurídica, atendimento de serviço social, psicologia e pedagogia. Após estes atendimentos, o mesmo foi encaminhado para o início do Programa, em que foi assinado um termo de consentimento, no qual se comprometeu a frequentar os oito módulos do curso, como também informado sobre as datas e horários que os encontros ocorreriam.

Com relação ao primeiro encontro, de acordo com os direcionamentos do Patronato Central do Estado, foi viabilizado ao agressor um espaço de acolhida e integração. Buscouse apresentar a metodologia do Programa, os horários, as temáticas que seriam abordadas, como também foram prestados esclarecimentos sobre as implicaçôes legais no caso de descumprimento. Neste encontro, foram utilizados recursos audiovisuais, como data show. Após, foi realizada uma dinâmica de apresentaçáo, no qual cada assistido escreveu 
em um sulfite o seu nome, e um desenho que o representava. Na sequência, cada um se levantou, se apresentou e apresentou os motivos pela escolha do desenho.

A reunião foi finalizada esclarecendo supostas dúvidas, estabelecendo-se um acordo que objetivou a organizaçáo durante as reuniôes. Nesta abordagem, citou-se sobre o uso indevido de celular nas reunióes, a não possibilidade de alimentação durante as reunióes e a não permissão de acompanhantes, tendo em vista o sigilo das informaçốes e os assuntos ali discutidos.

Já no segundo encontro, foi realizada a apresentação da Lei Maria da Penha, que teve como objetivo informar sobre a legislação na qual os agressores estavam enquadrados. Também foi apresentado um vídeo interativo sobre a história e contexto em que surgiu a lei. Em seguida, com auxílio de slides, foi apresentada de forma didática, clara e compreensível, o teor da Lei 11340/2006 e suas implicaçóes pelo técnico de serviço social. Enfatizou-se que a lei é abrangente, complexa e que esta legislaçáo caracteriza os tipos de violência, que excedem a dimensão física, atingindo a esfera psicológica, moral e espiritual. Após a explanação, abriu-se aos participantes um espaço de diálogo e esclarecimentos de dúvidas sobre a lei. $\mathrm{O}$ encontro foi finalizado com a assinatura da ficha de frequência.

O terceiro encontro foi conduzido pela profissional de psicologia, a qual buscou, por meio de recursos midiáticos, contextualizar a violência contra mulher na história, dando ênfase a subalternidade do sexo feminino nas sociedades antigas, sua exclusão dos processos políticos, do mercado de trabalho e demais acontecimentos. Através de slides e ilustraçóes acessíveis e de fácil compreensão, os assistidos puderam interagir e compreender com precisão o conteúdo exposto. Ao término da apresentaçáo, abriu-se espaço para discussão e reflexão sobre o tema abordado. Finalizou-se a reunião com os avisos e a assinatura da folha de frequência.

Já no quarto encontro, e de acordo com o planejamento prévio realizado, foi exibido o curta-metragem "Acorda Raimundo Acorda", de Alfredo Alves. O filme retrata questōes de gênero no Brasil, evidenciando a cultura machista entre as famílias de trabalhadores brasileiros, e relata a convivência cotidiana de uma família na qual os papéis de homem e mulher são invertidos. Com tal exibição, buscou-se fomentar, junto aos integrantes do grupo, um debate político sobre as relaçóes de gênero e a predominância da cultura machista ainda existente nas sociedades modernas, como também levá-los a refletir sobre as situaçôes similares e cotidianas que acontecem em suas famílias.

Já no quinto encontro, o objetivo central foi conduzi-los a repensar as dimensões da violência. Neste dia, foram apresentados termos conceituais sobre o assunto, esclarecendo que a violência se manifesta de diversas maneiras, como em guerras, torturas, conflitos étnicos religiosos, preconceito e assassinato, por exemplo, enfatizando que tal ato implica na violaçáo dos direitos humanos. Para que o objetivo proposto fosse atingido, foram apresentados dados relacionados ao feminicídio no Brasil. As informaçóes foram extraídas dos censos realizados nos últimos anos, além de informaçóes da pesquisa efetuada pela Organização Mundial da Saúde - OMS, sobre violência contra as mulheres, no ano de 2012.

Também foram apresentados ao grupo dados da Central de Atendimento à Mulher, mais especificamente do disk denúncia -180, canal criado, no ano de 2005, para prestar atendimento, orientação e encaminhamento das mulheres vítimas de violência doméstica aos órgãos competentes. Esses dados demonstraram que o tipo de violência mais recorrente foi a física, seguida da violência psicológica, violência moral e sexual. Já no que 
tange a relação da mulher com o agressor, os dados demonstraram que $49 \%$ ocorreram pelo companheiro.

Ainda neste encontro, houve um momento em que foi apresentada aos assistidos uma pesquisa realizada pelo Instituto Patrícia Galvão, em maio de 2013, sobre os crimes mais praticados no Brasil, que identificou que a violência contra mulher estava ocupando o terceiro lugar, estando abaixo apenas do assassinato e do crime de roubo/assalto.

Após a apresentação das informaçóes, partiu-se para o momento final de reflexão, por meio de cartazes de campanhas realizadas sobre violência contra a mulher, com imagens de mulheres agredidas, seguidos de frases indagadoras, do tipo: violência resolve? Quais as consequências dela na minha família? O que fazer para evitá-la no meu dia a dia? Finalizou-se a reunião com os avisos, passando-se, na sequência, para a coleta de assinaturas dos presentes.

Com relação ao sexto encontro, foi abordado o tema "Família e Sociedade". Pontuase que esta reuniáo teve como objetivo apresentar aos membros do grupo os diferentes arranjos familiares existentes na sociedade contemporânea, os quais excedem o modelo de família nuclear burguês, dando visibilidade às famílias monoparentais, chefiadas por mulheres ou homens, e as famílias formadas por casais homoafetivos. Esta abordagem foi capaz de levá-los a um exercício reflexivo sobre o preconceito ainda existente pela sociedade. Também se discutiu sobre os papéis no ambiente familiar e as formas de organização das famílias.

Ainda, foi explanado nesta reunião sobre as consequências da violência no ambiente familiar - sociais e psicológicas -, como rompimento de vínculos familiares e as implicaçóes jurídico-legais que ocasiona. Os membros do grupo participaram das discussóes propostas e deram suas contribuiçóes, com relatos de experiência.

O sétimo encontro teve como objetivo central levar os integrantes do grupo a refletir sobre o delito cometido. Através de uma dinâmica realizada pela profissional da área de psicologia, buscou-se pontuar as implicaçóes negativas da violência, independentemente de sua modalidade, na vida de cada um, e, consequentemente, levá-los a pensar se o ato violento resolveu os problemas e conflitos existentes no âmbito de relacionamento familiar. A dinâmica proposta foi realizada por meio da entrega de duas placas, uma escrita "sim" e outra escrita "não" a cada integrante. Assim, a profissional de psicologia fez questionamentos sobre assuntos relacionados à violência e suas consequências, e os integrantes do grupo levantavam as placas, expondo suas opiniôes.

Já no oitavo e último encontro, buscou-se, por meio de discussóes, identificar a percepçáo dos participantes em relação ao período que vivenciaram no grupo. Viabilizouse um espaço para diálogo, no qual se objetivou discutir as mudanças que ocorreram durante os oito encontros. A equipe técnica sintetizou com o grupo as discussóes e temas trabalhados nos encontros anteriores e, em seguida, os participantes foram convidados a comentar sobre as vivências nos encontros, os aprendizados e as contribuiçóes que o grupo reflexivo trouxe para cada um. Para o fechamento do programa, foram prestadas orientações sobre a situação processual de cada integrante, com vistas à efetivação do direito à informação. 


\section{Resultados alcançados}

Em geral, o Projeto de Extensão Patronato Municipal de Jacarezinho trouxe contribuiçôes significativas no que tange a execuçáo penal em meio aberto no município. Este, por meio de suas açôes conjuntas com o Poder Judiciário, viabilizou efetividade na fiscalização das alternativas penais, além de possibilitar a reinserção social dos envolvidos com práticas delituosas e a consequente diminuição da reincidência criminal e dos conflitos sociais.

Os programas de acompanhamento específicos garantiram e possibilitaram aos assistidos pelo Programa Patronato um espaço de reflexáo e informação, permitindo uma readequação de sua conduta social e sua reinserçáo na sociedade. Com relaçáo ao programa de acompanhamento específico - Programa Basta, este permitiu o acesso, por parte dos assistidos, a informaçóes antes desconhecidas, relacionadas à Lei Maria da Penha, o entendimento e esclarecimento sobre a situaçáo processual de cada um, como também uma mudança de paradigma e o rompimento das estruturas de sustentação da condição de subalternização das mulheres na história.

No decorrer dos encontros realizados, gradativamente, a equipe pôde perceber a conscientizaçáa dos assistidos para com as temáticas propostas. A exemplo, necessário mencionar a contribuição aferida no quarto encontro, no qual foi reproduzido o curta metragem "Acorda Raimunda, acorda", oportunidade em que muitos dos assistidos se identificaram com situaçóes apresentadas no filme, dando suas contribuiçóes, com relatos de experiências vivenciadas.

No quinto encontro, os assistidos foram levados a pensar a respeito das dimensóes da violência, por meio dos dados da Organizaçáo Mundial da Saúde, sobre tipos de violência contra a mulher, e também dados da Central de Atendimento à Mulher, a qual trata da relaçáo da vítima com o agressor. Logo, foi possível perceber que os membros do grupo ficaram espantados e até surpresos com tais números. Muitos mencionaram o desconhecimento de tal situação e dos dados alarmantes. Pontua-se a contribuição relacionada à desconstrução pelos participantes do grupo, no que tange a associação de violência somente ao ato físico. Eles aprenderam nas reunióes que existem outros tipos de violência e violação de direitos que atingem o campo emocional e material.

No sexto encontro, foi realizada uma explanação sobre o tema Família e Sociedade. Muitos dos membros do grupo delimitaram seu papel na família, pontuando a dimensão de provedor financeiro e cuidado dos filhos. Observou-se também que muitos reconheceram que as mulheres na família moderna, também desempenham o papel de provedora financeira e também estão inseridas na esfera produtiva.

Já no sétimo encontro, o qual tinha por intuito levar os assistidos a refletir sobre o delito cometido, observou-se que o objetivo proposto foi alcançado, pois muitos verbalizaram palavras de arrependimento, dizendo que o nervosismo culminou em atitudes não pensadas.

O último encontro visava identificar a percepção dos participantes a respeito do período que vivenciaram dentro do grupo. Todos os integrantes participaram da discussão, mencionando que o grupo foi um espaço onde puderam expor suas opinióes sobre determinados assuntos, sem o risco de sofrer represália. Também falaram sobre a importância do projeto no sistema de justiça, que viabiliza a reinserção social e não somente a repressão ao autor do delito. 
Além das contribuiçóes mencionadas, o Programa Basta permitiu um momento de interação entre os participantes, viabilizando a participação social, convívio social e o exercício democrático. As reunióes viabilizaram aos membros do grupo um espaço de escuta qualificada, em que puderam dizer o que pensavam, sem serem alvos de discriminação.

Destacam-se, também, as construçôes de projetos de vida pós-grupo e as açóes de responsabilizaçáo realizadas de modo a atingir os objetivos de cessar a violência contra a mulher, por conta do processo reflexivo. Também cabe mencionar o trabalho de articulaçáo realizado com os demais serviços da Rede de Atendimento à Mulher em situação de violência, em especial com o sistema de justiça (Juizados de Violência Doméstica e Familiar contra a Mulher, Ministério Público, Centrais de Medidas Alternativas, Secretarias Estaduais/Municipais de Justiça, Poder Judiciário etc.).

Além das contribuiçóes supracitadas, o Projeto Patronato Municipal, através do Programa Basta, viabilizou à populaçáo usuária do serviço o acesso efetivo ao sistema de justiça, como também a informaçóes claras e compreensíveis sobre a tramitação dos processos relacionados a eles.

\section{Consideraçóes Finais}

Com base na aplicação do Programa Basta, foi possível constatar, ao final dos encontros, uma mudança significativa no comportamento dos assistidos para com os temas debatidos. Os mesmos mostraram-se mais receptivos e, além disso, reconheceram suas falhas de conduta, o que resultou na sua participaçáo no Programa.

Até o momento, não foi possível a identificação de casos de reincidência pelos participantes, porém, cabe considerar a internalização de novas condutas e as novas posturas adotadas pós-grupo.

\section{Agradecimentos}

Ao Poder Judiciário de Jacarezinho e à equipe multidisciplinar do Patronato Municipal de Jacarezinho. À SEJU, SETI, PROEC - UENP e Prefeitura Municipal de Jacarezinho. 


\section{Referências}

BRASIL. Altera dispositivos do decreto-Lei 2848 de 7 de dezembro de 1940 - Código Penal. Lei no 9714, de 25 de novembro de 1998.

. Lei de Execução Penal no 7.210 de 11 de julho de 1984.

. Lei Maria da Penha. Lei no 11.340, de 7 de agosto de 2006.

. Presidência da República. Secretaria Especial de Políticas para as Mulheres SPM. Disponível em: < http://www.spm.gov.br/central-de-conteudos/publicacoes/ publicacoes/2015/balanco180_2014-versaoweb.pdf > Acesso em: 12. mai. 2015.

INSTITUTO PATRÍCIA GALVÃO. Percepção da sociedade sobre violência e assassinatos de mulheres. Disponível em: < http://agenciapatriciagalvao.org.br/violencia/pesquisa-ipeacatalisou-tensao-da-sociedade-em-relacao-violencia-de-genero-aponta-especialista/> Acesso em: 30. mai. 2015. 
JACAREZINHO. Lei nº. 2895, de 13 de setembro de 2013.

MENEGUEL, Stela Nazareth. Repercussões da Lei Maria da Penha no enfrentamento da violência de gênero. Ciência \& Saúde Coletiva, Rio de Janeiro, v.18, n.3, mar. 2013. Disponível em: < http://www.scielo.br/scielo. php?script=sci_arttext\&pid=S1413-81232013000300015 > Acesso em: 20 mai. 2015.

OLIVEIRA, Cinthia Mata de. Os beneficiários da prestação de serviço à comunidade como alternativa a pena de liberdade: experiências na Comarca de Duque de Caxias. 2011 105f. Dissertação (Mestrado) Departamento de Serviço Social, Pontifícia Universidade Católica do Rio de Janeiro, Rio de Janeiro, 2011.

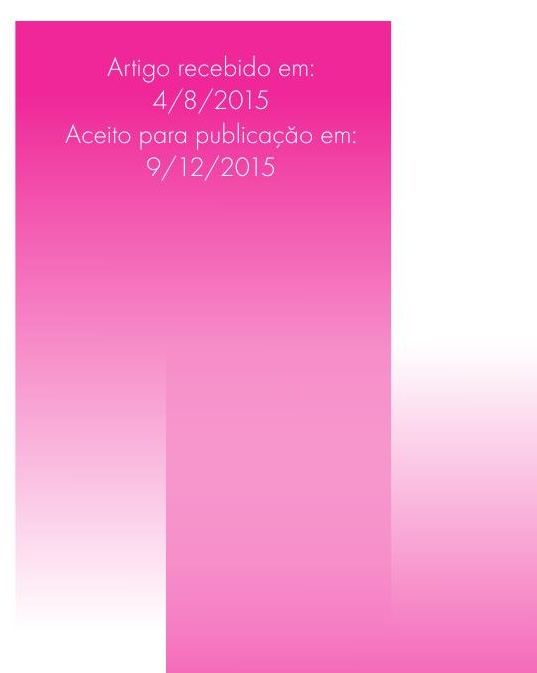

